\title{
BMJ Assessment of blood clot formation open and platelet receptor function ex vivo in patients with primary Sjögren's syndrome
}

\author{
K S Collins, ${ }^{1} \mathrm{~K}$ Balasubramaniam, ${ }^{2} \mathrm{G}$ Viswanathan, ${ }^{2}$ A Natasari, ${ }^{1} \mathrm{~J}$ Tarn, ${ }^{1}$ \\ D Lendrem, ${ }^{3} \mathrm{~S}$ Mitchell, ${ }^{3}$ A Zaman, ${ }^{2,3} \mathrm{~W} \mathrm{~F} \mathrm{Ng}^{1}$
}

To cite: Collins KS, Balasubramaniam K, Viswanathan $\mathrm{G}$, et al. Assessment of blood clot formation and platelet receptor function ex vivo in patients with primary Sjögren's syndrome. BMJ Open 2013;3:e002739. doi:10.1136/bmjopen-2013002739

- Prepublication history and additional material for this paper are available online. To view these files please visit the journal online (http://dx.doi.org/10.1136/ bmjopen-2013-002739).

Received 16 February 2013 Revised 14 April 2013 Accepted 19 April 2013

This final article is available for use under the terms of the Creative Commons Attribution Non-Commercial 2.0 Licence; see http://bmjopen.bmj.com

For numbered affiliations see end of article.

\section{Correspondence to}

Dr Azfar Zaman;

Azfar.Zaman@nuth.nhs.uk or Dr Wan-Fai Ng;

wan-fai.ng@ncl.ac.uk

\section{ABSTRACT}

Objectives: Primary Sjögren's syndrome (pSS) shares clinical features and pathogenetic mechanisms with systemic lupus erythematosus (SLE). SLE is associated with an increased thromboembolic risk; however, it is unclear whether pSS patients are susceptible to thromboembolic diseases. In this study, we examined ex vivo blood clot formation (clot strength, rates of clot formation and lysis) in pSS using thromboelastography (TEG) and platelet aggregation to common agonists using multiple electrode aggregometry (MEA). We also investigated the relationship between TEG/MEA parameters and clinical/laboratory features of $\mathrm{pSS}$.

Design: Case control.

Setting: Secondary care, single centre.

Participants: 34 pSS patients, 11 SLE patients and 13 healthy volunteers (all women) entered and completed the study.

\section{Primary and secondary outcome measures:}

Primary outcomes: TEG and MEA parameters between three subject groups. Secondary outcomes: The relationships between TEG/MEA and clinical/laboratory parameters analysed using bivariate correlation analysis with corrections for multiple testing.

Results: All TEG and MEA parameters were similar for the three subject groups. After corrections for multiple testing, interleukin (IL)-1 $\alpha$ and Macrophage inflammatory proteins (MIP)-1 $\alpha$ remain correlated inversely with clot strength $(r=-0.686, p=0.024$ and $r=$ $-0.730, p=0.012$, respectively) and overall coagulability $(r=-0.640, p=0.048$ and $r=-0.648, p=0.048)$. Stepwise regression analysis revealed that several cytokines such as MIP-1 $\alpha$, IL-17a, IL-1 $\alpha$ and Interferon (IFN)- $\gamma$ may be key predictors of clot strength and overall coagulability in $\mathrm{pSS}$.

Conclusions: Clot kinetics and platelet receptor function are normal in pSS. Several cytokines correlate with clot strength and overall coagulability in pSS.

\section{INTRODUCTION}

Primary Sjögren's syndrome (pSS) and systemic lupus erythematosus (SLE) share many

\section{ARTICLE SUMMARY}

Article focus

- To examine ex vivo blood clot formation and platelet aggregation in patients with primary Sjögren's syndrome ( $p S S$ ).

- To investigate the relationship between clinical and laboratory features of pSS and ex vivo coagulation and platelet aggregation.

Key messages

- The kinetics of blood clot formation and platelet aggregation in pSS is normal.

- Several cytokines such as MIP-1 $\alpha$, IL-17a, IL-1 $\alpha$ and IFN- $\gamma$ may correlate with clot strength and overall coagulability in pSS.

Strengths and limitations of this study

- This is the first study to examine ex vivo clot kinetics and platelet aggregation in whole blood of patients with pSS.

- The correlation between serum MIP-1 $\alpha$ and $\mathrm{IL}-1 \alpha$ and clot strength/overall coagulability is a novel observation.

- The sample size was relatively small.

clinical and pathobiological features. ${ }^{1}$ In SLE, many clinical and scientific studies have confirmed an increased risk of thrombosis, ${ }^{2}{ }^{3}$ accelerated atherosclerosis and higher cardiovascular morbidity and mortality. ${ }^{4}$ To date, data on thrombosis and thromboembolic risk in pSS are limited.

Theander et a $\check{P}$ found no increase in ischaemic cardiovascular mortality in pSS patients compared with the general population. The incidence of thromboembolic events (TEEs) in pSS patients $(1.44 / 100$ patient-years) was less than that for SLE patients $(2.9 / 100$ patient-years). ${ }^{2} 6$ The incidence of venous thromboembolism was higher in pSS patients compared with the normal population $(0.48$ events/100 patient-years ${ }^{6}$ vs $0.07-0.1$ events/ 100 patient-years ${ }^{7-9}$ ), but the incidence of 
arterial TEE was similar $\left(0.96 / 100\right.$ vs $0.94 / 100$ years $\left.{ }^{10}\right)$. The risk of pulmonary embolism during the first year after admission was high with pSS patients having a standardised incidence ratio of $7.4 .^{3}$

Several clinical and laboratory observations support an increased thrombotic potential in pSS. First, pSS patients may have abnormal lipid profiles, ${ }^{11}$ accelerated atherosclerosis $^{12}$ and increased prevalence of diabetes ${ }^{13}$ and hypertension (unpublished observations), all of which are risk factors for thromboembolic diseases. In addition, it has been reported that the prevalence of antiphospholipid antibodies is increased among pSS patients, ${ }^{14-18}$ which in turn may increase the thromboembolic risk. Second, there is an increase in microparticles, small membrane-bound vesicles secreted from activated/apoptotic cells, in pSS patients compared with controls and SLE patients. ${ }^{19}$ These microparticles are implicated in the initiation/propagation of thrombus and are associated with excessive thrombotic risk in rheumatoid arthritis and SLE. ${ }^{19}{ }^{20}$ Third, other factors associated with pSS, such as elevated levels of inflammatory cytokines and immunoglobulins and reduced complement levels, have also been linked to thrombosis. ${ }^{21-23}$

Haemostasis is a complex process which involves interactions between platelets, coagulation factors and the blood vessel wall. Clot formation and resolution is therefore dependent on platelet function, 'coagulability' of the blood and vascular endothelium. Various tests can be used to assess coagulation ex vivo. Thromboelastography (TEG) enables a functional evaluation of the coagulation cascade in whole blood, from clot formation to clot lysis, ${ }^{24}{ }^{25}$ whereas multiple electrode aggregometry (MEA) allows rapid assessment of the function of specific platelet receptors in whole blood. ${ }^{26}$ The use of whole blood has an advantage that it mimics more closely the in vivo conditions.

In this study, we used TEG and MEA to investigate whether ex vivo clotting is altered in pSS patients compared with healthy individuals. SLE patients were used as a disease comparator group. Additionally, we explored the relationships between clotting parameters and the clinical and laboratory data of pSS.

\section{METHODS}

Participants

All patients were recruited from the Freeman Hospital, Newcastle-upon-Tyne, UK, or Newcastle University (see online supplementary document 1), following informed consent according to the principles of the Helsinki Declaration. Sunderland research ethics committee has approved the study. The inclusion/exclusion criteria are listed in online supplementary table S1. We initially studied 18 healthy controls, and found significant differences in many TEG parameters between male and female volunteers (see online supplementary table S2). Since the majority of pSS/SLE patients are women, in order to avoid the confounding effect of gender difference on clot kinetics, we have analysed the data from female participants only.

\section{TEG and MEA}

Blood samples were collected using $18 \mathrm{G}$ needles and vacutainer tubes containing citrate (for TEG) or hirudin (for MEA). Clinical and laboratory data were collected from medical records and from the UK Primary Sjögren's Registry (UKPSSR). ${ }^{27}$ All samples were analysed within $45 \mathrm{~min}$ to $3 \mathrm{~h}$ after collection as per manufacturers' guidance.

\section{Thromboelastography}

A TEG 5000 Haemostasis Analyser (Haemoscope Inc, USA) was used and data were analysed using the TEG Analytical Software, V.4.1.54. Briefly, $1 \mathrm{ml}$ of blood sample was transferred to a vial containing kaolin to activate the clotting cascade. In total, $340 \mu \mathrm{l}$ was then transferred to a TEG vial with $20 \mu \mathrm{CaCl}_{2}$ which chelates citrate and promotes thrombogenesis. A TEG trace (see online supplementary figure S1) was produced over $90 \mathrm{~min}$. The following parameters corresponding to various components of the clotting process were recorded: $\mathrm{R}$ time, $\mathrm{K}$ time, $\alpha$ angle, maximum amplitude (MA), LY30, LY60 and clotting index (CI).

\section{Multiple electrode aggregometry}

A multiplate analyser (Dynabyte, Munich, Germany) with integrated software was used. Briefly, blood samples were diluted with $0.9 \%$ saline solution (1:1), after $3 \mathrm{~min}$ of incubation $\left(37^{\circ} \mathrm{C}\right)$, the corresponding agonists $(20 \mu \mathrm{l})$ for four different platelet receptor pathways (cyclooxygenase: archidonic acid; P2Y12: ADP; thrombin: thrombin receptor-activating peptide; glycoprotein Ib: collagen) were added. Platelet aggregation enhances the electrical resistance on the duplicate sensors, which was transformed to arbitrary aggregation units for each agonist.

\section{Serum soluble molecules measurement}

Serum levels of various soluble molecules (see online supplementary table S3) from pSS patients $(n=18)$ were measured using Cytometric Bead Array (Becton Dickinson, Oxford, UK) according to manufacturer's protocol. Briefly, capture beads for the corresponding analytes were added to diluted serum samples. After $1 \mathrm{~h}$ of incubation (room temperature), PE detection reagents were added and incubated for $2 \mathrm{~h}$, the samples were then washed, resuspended and analysed with a flow cytometer (BD LSR-II) and the FCAP Array software.

\section{Statistical analysis}

Minitab (V.16) and SPSS (V.19.0) were used for statistical analysis. One-way analysis of variance and Kruskal-Wallis tests were used for group comparisons of parametric and non-parametric data. Pearson's correlation was used to analyse the relationships between the TEG/MEA data and clinical/laboratory data. $\mathrm{p}$ Values were corrected for 
multiple testing using Benjamini-Hochberg procedure. Stepwise regression analyses were performed using MA or CI as dependent variable. Factor analysis was used to identify independent factors among the cytokine data for stepwise regression analysis to avoid the problem of multicollinearity.

\section{RESULTS}

\section{Cohort characteristics}

Table 1 summarises the baseline characteristics for the three subject groups. There were significant differences between groups for age. Compared with pSS patients, the average disease duration was longer for SLE patients ( 4.6 vs 13 years, $\mathrm{p}=0.016$ ), and a higher proportion was taking steroids.

\section{TEG and MEA}

All TEG and MEA parameters were similar between pSS patients, SLE patients and healthy controls (table 2). The proportion of individuals in each subject group with TEG/MEA parameters outside the 'reference ranges' was also similar (data not shown). These observations indicate that there are no significant differences in the clot strength, rate of clot formation and lysis and platelet receptor function ex vivo between the three subject groups.

\section{Relationships between clinical/laboratory data of pSS and TEG/MEA parameters}

Several serum cytokines/chemokines (interleukin (IL)-1 $\alpha$, IL-17a, IL-21, tumour necrosis factor- $\alpha$, MIP-1 $\alpha$ ) and clinical laboratory measurements (erythrocyte sedimentation rate, $\mathrm{C}$ reactive protein, immunoglobulin $\mathrm{M}$, platelet count) correlated with some TEG/MEA parameters (see online supplementary table S3). Upon corrections for multiple testing, however, only MIP- $1 \alpha$ and IL- $1 \alpha$ remained negatively correlated with clot strength $(\mathrm{r}=-0.730$ and -0.686 ; corrected $\mathrm{p}=0.012$ and 0.024 , respectively) and overall coagulability (CI; $\mathrm{r}=-0.640$ and -0.648 ; both corrected $\mathrm{p}=0.048$; figure 1 ). Stepwise regression revealed MIP- $1 \alpha$ and IL-1 $\alpha$ as independent predictors for clot strength ( $\mathrm{p}=0.001$, adjusted $\left.\mathrm{r}^{2}=0.498\right)$ and overall coagulability ( $\mathrm{p}=0.005, \mathrm{r}^{2}=0.381$ ), respectively.

As anticipated, there were significant correlations (table 3) between many cytokines given the known physiological links between some of these cytokines. However, some of these correlations were particularly strong (eg, between IL- $1 \alpha$, MIP- $1 \alpha$, IL-17a and IL-21 $(\mathrm{R}>0.8))$, suggesting potential multicollinearity which may in turn be susceptible to over-fitting of the regression model. In order to mitigate the problem with multicollinearity, we first performed a factor analysis to identify independent factors within the cytokine data (see online supplementary table S4), and used these factors as independent variables in stepwise regression. For clot strength (MA), we identified factor 1 (which was predominantly represented by IL- $1 \alpha$, MIP- $1 \alpha$ and IL-17a) being the key predictor $(\mathrm{r}=0.69, \mathrm{p}=0.002$; table $4 \mathrm{~A})$. For CI, the key independent predictors were factors 1 and 7 ( $\mathrm{r}=0.807, \mathrm{p}=0.021$; table $4 \mathrm{~B})$. The latter was predominantly represented by IFN- $\gamma$. Taken together, our data suggest that several cytokines such as MIP- $1 \alpha$, IL-17a, IL-1 $\alpha$ and IFN- $\gamma$ may correlate with clot strength and overall coagulability.

\section{DISCUSSION}

In this study, we found no significant differences in ex vivo clot kinetics and platelet aggregation upon stimulation by various agonists in whole blood between patients with pSS, SLE and healthy volunteers. However, several inflammatory parameters were associated with ex vivo clotting parameters. Our findings in this population are novel and to our knowledge not yet reported.

In 1986, Oxholm et $a l^{28}$ reported that platelet aggregation (using Dual Channel Payton Aggregometer) in platelet-rich plasma of pSS patients was increased

Table 1 Demographics and clinical characteristics of the subject groups

\begin{tabular}{|c|c|c|c|c|}
\hline & pSS & SLE & Healthy controls & p Values \\
\hline Sample size & 34 & 11 & 13 & \\
\hline Age (years, mean (range)) & $58(30-83)$ & $45(20-78)$ & $35(22-54)$ & $<0.001$ \\
\hline Disease duration (years, mean (range)) & $4.6(1-15)$ & $13(4-28)$ & $N / A$ & 0.016 \\
\hline Anti-Ro/anti-La positive (number (\%)) & $26(76)$ & $4(36)$ & $\mathrm{N} / \mathrm{A}$ & 0.026 \\
\hline ESSDAI (mean (range)) & $4.2(0-15)$ & $N / A$ & N/A & - \\
\hline ESSPRI (mean (range)) & $5(1.7-9.7)$ & $\mathrm{N} / \mathrm{A}$ & $N / A$ & - \\
\hline Hydroxychloroquine use (number (\%)) & $16(47)$ & $6(54)$ & 0 & 0.666 \\
\hline Steroid use (number (\%)) & $3(9)$ & $5(45)$ & 0 & 0.006 \\
\hline Antihypertensive use (number (\%)) & $8(24)$ & $2(18)$ & 0 & 0.711 \\
\hline Platelet count (mean \pm SD (range), $\left.\times 10^{9} / \mathrm{I}\right)$ & $266 \pm 44(205-436)$ & $236 \pm 65(136-383)$ & $\mathrm{N} / \mathrm{A}$ & 0.053 \\
\hline Positive cardiovascular history* (number (\%)) & $1(3)$ & $0(0)$ & $\mathrm{N} / \mathrm{A}$ & 1.000 \\
\hline $\begin{array}{l}\text { Positive thromboembolioc/pregnancy } \\
\text { loss }(>1) \text { history* (number }(\%) \text { ) }\end{array}$ & $1(3)$ & $0(0)$ & $N / A$ & 1.000 \\
\hline
\end{tabular}


Table 2 TEG and MEA parameters for pSS patients, SLE patients and healthy controls

(A) TEG

\begin{tabular}{|c|c|c|c|c|c|c|c|}
\hline & \multicolumn{7}{|c|}{ TEG parameters } \\
\hline & R (mins) & $\mathrm{K}$ (mins)* & $\alpha$ Angle (degrees) ${ }^{*}$ & MA (mm) & LY30 (\%)* & LY60 (\%) & $\mathbf{C l}$ \\
\hline $\mathrm{pSS}(\mathrm{n}=34)$ & $5.5 \pm 1.3$ & $1.5 \pm 0.5$ & $68.1 \pm 5.5$ & $65.7 \pm 3.7$ & $0.7 \pm 1.7$ & $4.2 \pm 2.7$ & $1.2 \pm 1.5$ \\
\hline SLE $(n=11)$ & $5.0 \pm 0.8$ & $1.5 \pm 0.5$ & $69.0 \pm 4.4$ & $64.6 \pm 4.0$ & $1.2 \pm 2.2$ & $4.9 \pm 2.6$ & $1.6 \pm 1.1$ \\
\hline Healthy controls $(n=13)$ & $5.3 \pm 1.2$ & $1.5 \pm 0.4$ & $68.8 \pm 3.2$ & $66.2 \pm 5.3$ & $0.7 \pm 0.8$ & $3.6 \pm 1.3$ & $1.4 \pm 1.7$ \\
\hline p Value (ANOVA/Kruskal-Wallis) & 0.342 & 0.703 & 0.561 & 0.637 & 0.286 & 0.462 & 0.664 \\
\hline
\end{tabular}

(B) MEA

\begin{tabular}{lllll}
\hline & MEA parameters & & \\
\cline { 2 - 5 } & AA (AU) & ADP (AU) & TRAP (AU) & COL (AU) \\
\hline pSS $(n=34)$ & $89.4 \pm 22.3$ & $77.6 \pm 21.0$ & $101.1 \pm 22.7$ & $75.2 \pm 20.5$ \\
SLE $(n=11)$ & $93.5 \pm 26.5$ & $71.1 \pm 21.3$ & $96.3 \pm 33.6$ & $77.0 \pm 24.5$ \\
Healthy controls $(n=13)$ & $85.3 \pm 33.4$ & $69.4 \pm 27.4$ & $88.6 \pm 35.4$ & 0.893 \\
p Value (Anova/Kruskal-Wallis) & 0.752 & 0.515 & 0.419 & 727.5 \\
\hline
\end{tabular}

Normally distributed values are presented as mean \pm SD. Non-normally distributed values (asterisk) are presented as median \pm IQR. Aggregate unit $(A U)$ values (mean $\pm S D$ ) shown for the platelet receptor agonists $A A, A D P, C O L$ and TRAP.

$\mathrm{AA}$, archidonic acid; ANOVA, analysis of variance; $\mathrm{Cl}$, clotting index; COL, collagen; MEA, multiple electrode aggregometry; pSS, Primary Sjögren's syndrome; SLE, systemic lupus erythematosus; TEG, thromboelastography; TRAP, thrombin receptor-activating peptide.

compared with healthy controls. However, there are important differences between the study by Oxholm et al and our study. First, the classification criteria used for pSS patients were different. Before the AECG consensus criteria 2002 were developed, studies of pSS used different criteria for the disease, which has been a potential reason for many discrepant data in pSS. AECG criteria are arguably the most widely accepted classification criteria for pSS to date. Second, Oxholm et al studied platelet aggregation in 'isolation', whereas in our study, platelet aggregation was measured in 'whole blood',
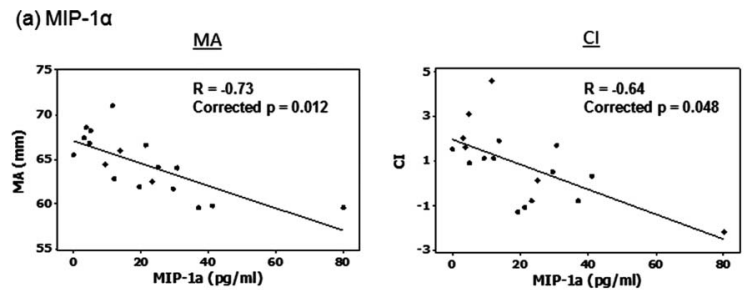

(b) IL-1a
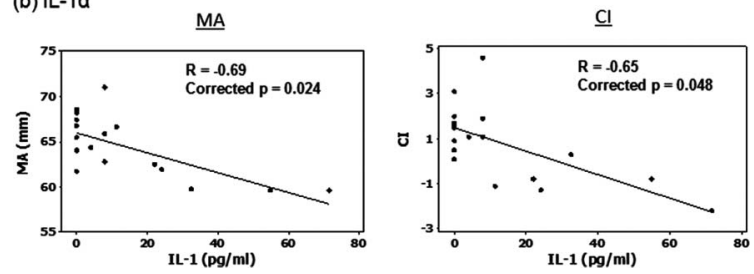

Figure 1 Correlation between clinical and laboratory parameters of primary Sjögren's syndrome and thromboelastography (TEG) values. (A) MIP-1 $\alpha$ and (B) interleukin (IL)-1 $\alpha$. Only variables that have statistical significant correlations with TEG measurements after corrections for multiple testing are shown. The lower limits of detection for MIP- $1 \alpha$ and IL- $1 \alpha$ were 0.2 and $1 \mathrm{pg} / \mathrm{ml}$, respectively. which we believe is more physiologically relevant. In addition, the process of platelet enrichment can activate platelet and may introduce variability to the data. In contrast, the MEA method we used in this study involved minimal handling of the samples. Third, the methods used for measuring platelet aggregation and how the results are presented differ between the two studies.

The three subject groups differed in age, but we found no correlation between age and TEG/MEA parameters in healthy controls (see online supplementary table S2). Since patients taking antiplatelet agents or anticoagulants were excluded, clotting/platelet receptor abnormalities in pSS could have been underestimated. However, of the 639 pSS patients from the UKPSSR, only $10 \%$ and $3 \%$ were taking aspirin/clopidigrel and warfarin, respectively (unpublished data). The pSS group in this study has relatively short disease duration, but we found no correlation between disease duration and any TEG/MEA parameters. The sample size of this study was relatively small, but the mean/median values of all the test parameters were remarkably similar between the subject groups and the SDs for many TEG parameters were small.

Since there were no significant difference in clotting between SLE patients and healthy controls, our data suggest that alternative mechanisms such as in vivo factors (eg, endothelial dysfunction), traditional cardiovascular risk factors or other yet undefined mechanisms may be responsible for the increased thromboembolic risk in SLE.

Platelet number and function are important determinants of TEG/MEA parameters. In this study, the platelet counts in the pSS group were within normal range and there was no significant difference in platelet counts between the pSS and SLE groups. Although there were 
Table 3 Bivariate correlations between serum cytokines and soluble molecules

\begin{tabular}{|c|c|c|c|c|c|c|c|c|c|c|c|c|}
\hline & \multicolumn{12}{|c|}{ Correlations (Pearson's r value) } \\
\hline & IL-1 & 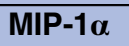 & IL-8 & IFN- $\gamma$ & IL-6 & IL-1及 & IL-12p70 & IL-10 & CD40L & IL-17a & TNF- $\alpha$ & IL-21 \\
\hline IL-1 $\alpha$ & 1 & $0.832^{*}$ & -0.266 & 0.339 & -0.222 & -0.13 & 0.392 & 0.119 & -0.366 & $0.823^{*}$ & $0.668^{*}$ & $0.837^{*}$ \\
\hline MIP $-1 \alpha$ & $0.832^{*}$ & 1 & 0.195 & 0.109 & 0.171 & -0.109 & 0.18 & 0.095 & -0.018 & $0.761^{*}$ & $0.608^{*}$ & $0.696^{*}$ \\
\hline IL-8 & -0.266 & 0.195 & 1 & -0.466 & $0.789^{\star}$ & -0.071 & -0.191 & 0.122 & $0.666^{*}$ & -0.225 & -0.094 & -0.217 \\
\hline IFN- $\gamma$ & 0.339 & 0.109 & -0.466 & 1 & -0.328 & 0.252 & 0.334 & 0.085 & $-0.538 \dagger$ & 0.224 & 0.122 & 0.264 \\
\hline IL-6 & -0.222 & 0.171 & $0.789^{\star}$ & -0.328 & 1 & 0.09 & -0.177 & 0.04 & 0.365 & -0.168 & -0.115 & -0.219 \\
\hline IL-1 $\beta$ & -0.13 & -0.109 & -0.071 & 0.252 & 0.09 & 1 & -0.026 & 0.026 & -0.134 & 0.21 & -0.06 & -0.191 \\
\hline IL-12p70 & 0.392 & 0.18 & -0.191 & 0.334 & -0.177 & -0.026 & 1 & $0.571 \dagger$ & -0.231 & 0.234 & 0.369 & $0.547 \dagger$ \\
\hline IL-10 & 0.119 & 0.095 & 0.122 & 0.085 & 0.04 & 0.026 & $0.571 \dagger$ & 1 & 0.184 & 0.149 & 0.455 & 0.246 \\
\hline CD40L & -0.366 & -0.018 & $0.666^{\star}$ & $-0.538 \dagger$ & 0.365 & -0.134 & -0.231 & 0.184 & 1 & -0.153 & 0 & -0.303 \\
\hline IL-17a & $0.823^{*}$ & $0.761^{*}$ & -0.225 & 0.224 & -0.168 & 0.21 & 0.234 & 0.149 & -0.153 & 1 & $0.760^{*}$ & $0.563 \dagger$ \\
\hline TNF- $\alpha$ & $0.668^{*}$ & $0.608^{*}$ & -0.094 & 0.122 & -0.115 & -0.06 & 0.369 & 0.455 & 0 & $0.760^{\star}$ & 1 & 0.437 \\
\hline IL-21 & $0.837^{\star}$ & $0.696^{*}$ & -0.217 & 0.264 & -0.219 & -0.191 & $0.547 \dagger$ & 0.246 & -0.303 & $0.563 \dagger$ & 0.437 & 1 \\
\hline
\end{tabular}

${ }^{*}$ Correlation is significant at the 0.01 level (two-tailed).

tCorrelation is significant at the 0.05 level (two-tailed).

IL, interleukin; TNF, tumour necrosis factor.

marginally significant inverse correlations between platelet counts and Ly30 ( $\mathrm{r}=-0.359, \mathrm{p}=0.040$ (uncorrected)) as well as Ly60 ( $\mathrm{r}=-0.355, \mathrm{p}=0.042$ (uncorrected)) on bivariate correlation analysis, such correlations were no longer statistically significant on corrections for multiple comparison (see online supplementary table S3).

Hydroxychloroquine is associated with reduced cardiovascular events and anti-phospholipid antibody-mediated platelet activation in SLE. ${ }^{29}$ Since approximately half of the pSS and SLE group was taking hydroxychloroquine, this may mask the clotting abnormalities among the patient groups. However, there were no significant difference in any of the TEG and MEA parameters between patients who were receiving hydroxychloroquine treatment and those who were not in this study (see online supplementary table S5). We could not exclude, however, that patients receiving hydroxychloroquine therapy might have abnormal clot kinetics or platelet aggregation prior to treatment.

The presence of antiphospholipid antibodies have been reported in pSS patients and may contribute to increased thromboembolic risk. ${ }^{14-18}$ In our study, antiphospholipid antibodies were not systematically tested in the patients although at least three pSS patients were positive for antiphospholipid antibodies. Future studies investigating whether the presence of antiphospholipid antibodies affect TEG/MEA parameters is worthwhile.

A novel observation in this study is the negative correlation between the serum levels of several proinflammatory molecules such as MIP- $1 \alpha /$ IL- $1 \alpha$ and clot strength/overall coagulability. Consistent with our findings, $\mathrm{Ng}$ et $a l^{30}$ reported serum IL-6 levels to be inversely correlated with clot strength and CI in posthepatobiliary surgery patients. These observations initially appeared contradictory to the link between inflammation and increased TEEs. ${ }^{31}$ However, many of the potential mechanisms by which inflammatory molecules promote thrombogenesis relate to in vivo phenomena such as endothelial cell dysfunction and tissue factor-mediated activation of coagulation. ${ }^{22} 32$ Another possibility for the inverse correlation between inflammation and TEG parameters could be prior platelet activation because previously activated platelets might be less ready to participate in coagulation and platelet

Table 4 Identify independent predictors of clot strength and clotting index using factor analysis approach

\begin{tabular}{|c|c|c|c|c|c|c|c|}
\hline \multirow[b]{2}{*}{ Model } & \multicolumn{2}{|c|}{$\begin{array}{l}\text { Unstandardised } \\
\text { coefficients }\end{array}$} & \multicolumn{3}{|c|}{$\begin{array}{l}\text { Standardised } \\
\text { coefficients }\end{array}$} & \multicolumn{2}{|l|}{$\begin{array}{l}\text { Collinearity } \\
\text { statistics }\end{array}$} \\
\hline & $\overline{\mathbf{B}}$ & SE & $\overline{\boldsymbol{\beta}}$ & $\mathbf{t}$ & Significance & Tolerance & VIF \\
\hline \multicolumn{8}{|l|}{ (A) Independent predictor of clot strength } \\
\hline (Constant) & 64.382 & 0.615 & & 104.746 & 0 & & \\
\hline REGR factor score 1 for analysis 1 & -2.336 & 0.634 & -0.69 & -3.687 & 0.002 & 1 & 1 \\
\hline \multicolumn{8}{|l|}{$\begin{array}{l}r=0.690, r^{2}=0.475 \text {, adjusted } r^{2}=0.44 \\
\text { (B) Independent predictor of clotting index }\end{array}$} \\
\hline (Constant) & 0.724 & 0.26 & & 2.779 & 0.015 & & \\
\hline REGR factor score 1 for analysis 1 & -1.18 & 0.268 & -0.694 & -4.395 & 0.001 & 1 & 1 \\
\hline $\begin{array}{l}\text { REGR factor score } 7 \text { for analysis } 1 \\
r=0.807, r^{2}=0.651, \text { adjusted } r^{2}=0.601\end{array}$ & 0.697 & 0.268 & 0.41 & 2.596 & 0.021 & 1 & 1 \\
\hline
\end{tabular}


aggregation compared with non-activated platelets. It is therefore of interest that platelet activation has been linked with an upregulation of the type I interferon signature in SLE, ${ }^{33}$ as a similar gene signature has also been described in the peripheral blood samples of pSS patients. ${ }^{34} 35$ However, in this study, soluble CD40L, a potential marker of platelet activation did not correlate with the TEG/MEA parameters. More detailed studies of the relationships between prior platelet activation and clot kinetics and platelet aggregation would be of interest. In TEG, clot strength is determined by platelet number and function, as well as cross-linking of fibrin to form a stable clot. In this study, neither MIP- $1 \alpha$ nor IL- $1 \alpha$ correlated with platelet counts $(\mathrm{r}=-0.146, \mathrm{p}=0.575$ and $\mathrm{r}=-0.130, \mathrm{p}=0.619$, respectively). Fibrinogen levels were not measured and therefore a role for MIP-1 $\alpha$ or IL-1 $\alpha$ in fibrin cross-linking cannot be excluded. Low levels of CCR1, receptor for MIP-1 $\alpha$, are expressed on platelets, but its function is unclear. $^{36}$ An intriguing possibility is that MIP- $1 \alpha$ may provide a negative feedback mechanism on platelet function. Further research into the mechanistic link between these cytokine/ chemokine and hypocoagulability is warranted.

\section{Author affiliations}

${ }^{1}$ Musculoskeletal Research Group, Institute of Cellular Medicine, Newcastle University, Newcastle upon Tyne, UK

${ }^{2}$ Department of Cardiovascular Medicine, Institute of Cellular Medicine, Newcastle University, Newcastle upon Tyne, UK

${ }^{3}$ Musculoskeletal Directorate, Newcastle upon Tyne Hospitals NHS Foundation Trust, Newcastle upon Tyne, UK

Acknowledgements The authors would like to thank all the patients and healthy volunteers who have participated in this study.

Contributors WFN, GV and AZ conceptualised the study. AZ, WFN and KSC designed the study. KSC and WFN wrote the manuscript. KSC, KB, AN and SM collected the data. KSC, WFN, AN, JT, DL and AZ performed the data analysis and interpretation. All authors have involved in the writing of the manuscript. They read and approved the final manuscript.

Funding Graham and Jenny Watson Bursary provided stipends for lead author KSC. The UKPSSR (which provided some of the clinical data for this study) was funded by the Medical Research Council, UK (Grant number: G0800629)).

Competing interests None.

Patient consent Obtained.

Ethics approval Sunderland Research Ethics Committee, UK.

Provenance and peer review Not commissioned; externally peer reviewed.

Data sharing statement The majority of the data analysis has been provided in the main documents or as supplementary files. Request for access to raw data can be made by contacting authors KSC or WFN.

\section{REFERENCES}

1. Perl A. Emerging new pathways of pathogenesis and targets for treatment in systemic lupus erythematosus and Sjogren's syndrome. Curr Opin Rheumatol 2009;21:443-7.

2. Mok CC, Tang SS, To $\mathrm{CH}$, et al. Incidence and risk factors of thromboembolism in systemic lupus erythematosus: a comparison of three ethnic groups. Arthritis Rheum 2005;52:2774-82

3. Zoller B, Li X, Sundquist J, et al. Risk of pulmonary embolism in patients with autoimmune disorders: a nationwide follow-up study from Sweden. Lancet 2012;379:244-9.

4. Sherer $Y$, Shoenfeld Y. Mechanisms of disease: atherosclerosis in autoimmune diseases. Nat Clin Pract 2006;2:99-106.
5. Theander E, Manthorpe R, Jacobsson LT. Mortality and causes of death in primary Sjogren's syndrome: a prospective cohort study. Arthritis Rheum 2004;50:1262-9.

6. Haga HJ, Jacobsen EM, Peen E. Incidence of thromboembolic events in patients with primary Sjogren's syndrome. Scand $J$ Rheumatol 2008;37:127-9.

7. White $\mathrm{RH}$. The epidemiology of venous thromboembolism. Circulation 2003;107(23 Suppl 1):14-8.

8. Silverstein MD, Heit JA, Mohr DN, et al. Trends in the incidence of deep vein thrombosis and pulmonary embolism: a 25-year population-based study. Arch Intern Med 1998;158:585-93.

9. Petrauskiene V, Falk M, Waernbaum I, et al. The risk of venous thromboembolism is markedly elevated in patients with diabetes. Diabetologia 2005;48:1017-21.

10. Rothwell PM, Coull AJ, Silver LE, et al. Population-based study of event-rate, incidence, case fatality, and mortality for all acute vascular events in all arterial territories (Oxford Vascular Study). Lancet 2005;366:1773-83.

11. Lodde BM, Sankar V, Kok MR, et al. Serum lipid levels in Sjogren's syndrome. Rheumatology (Oxford, England) 2006;45:481-4.

12. Bartoloni E, Shoenfeld Y, Gerli R. Inflammatory and autoimmune mechanisms in the induction of atherosclerotic damage in systemic rheumatic diseases: two faces of the same coin. Arthritis Care Res (Hoboken) 2011;63:178-83.

13. Perez-De-Lis M, Akasbi M, Siso A, et al. Cardiovascular risk factors in primary Sjogren's syndrome: a case-control study in 624 patients. Lupus 2010;19:941-8.

14. Fauchais AL, Lambert M, Launay D, et al. Antiphospholipid antibodies in primary Sjogren's syndrome: prevalence and clinical significance in a series of 74 patients. Lupus 2004;13:245-8.

15. Pasoto SG, Chakkour HP, Natalino RR, et al. Lupus anticoagulant: a marker for stroke and venous thrombosis in primary Sjogren's syndrome. Clin Rheumatol 2012;31:1331-8.

16. Asherson RA, Fei HM, Staub HL, et al. Antiphospholipid antibodies and HLA associations in primary Sjogren's syndrome. Ann Rheum Dis 1992;51:495-8.

17. Jedryka-Goral A, Jagiello P, D'Cruz DP, et al. Isotype profile and clinical relevance of anticardiolipin antibodies in Sjogren's syndrome. Ann Rheum Dis 1992;51:889-91.

18. Cervera R, Garcia-Carrasco M, Font J, et al. Antiphospholipid antibodies in primary Sjogren's syndrome: prevalence and clinical significance in a series of 80 patients. Clin Exp Rheumatol 1997;15:361-5.

19. Sellam J, Proulle V, Jungel A, et al. Increased levels of circulating microparticles in primary Sjogren's syndrome, systemic lupus erythematosus and rheumatoid arthritis and relation with disease activity. Arthritis Res Ther 2009;11:R156.

20. Ardoin SP, Shanahan JC, Pisetsky DS. The role of microparticles in inflammation and thrombosis. Scand J Immunol 2007;66:159-65.

21. Oikonomopoulou K, Ricklin D, Ward PA, et al. Interactions between coagulation and complement-their role in inflammation. Semin Immunopathol 2012;34:151-65.

22. Grignani G, Maiolo A. Cytokines and hemostasis. Haematologica 2000;85:967-72.

23. Mehta J, Singhal S. Hyperviscosity syndrome in plasma cell dyscrasias. Semin Thromb Hemost 2003;29:467-71.

24. Wegner J, Popovsky MA. Clinical utility of thromboelastography: one size does not fit all. Semin Thromb Hemost 2010;36:699-706.

25. Scarpelini S, Rhind SG, Nascimento B, et al. Normal range values for thromboelastography in healthy adult volunteers. Braz J Med Biol Res 2009;42:1210-17.

26. Lee KR, Verheyden VJ, Mumford AD. Evaluation of multiple electrode aggregometry in whole blood using multiplate mini test cells. Thromb Res 2012;129:e59-64.

27. Ng WF, Bowman SJ, Griffiths B. United Kingdom Primary Sjogren's Syndrome Registry-a united effort to tackle an orphan rheumatic disease. Rheumatology (Oxford, England) 2011;50:32-9.

28. Oxholm $\mathrm{P}$, Winther $\mathrm{K}$, Manthorpe R. Platelet function in patients with primary Sjögren's syndrome. Acta Med Scand 1986;219:85-90.

29. Espinola RG, Pierangeli SS, Gharavi AE, et al. Hydroxychloroquine reverses platelet activation induced by human IgG antiphospholipid antibodies. Thromb Haemost 2002;87:518-22.

30. $\mathrm{Ng} \mathrm{KF}$, Ip MS, Ho ET, et al. Coagulation and cytokine profile after major hepatobiliary surgery in Chinese patients. Hepatogastroenterology 2000;47:1067-71.

31. Gurbel PA, Bliden KP, Kreutz RP, et al. The link between heightened thrombogenicity and inflammation: pre-procedure characterization of the patient at high risk for recurrent events after stenting. Platelets 2009;20:97-104.

32. Shebuski RJ, Kilgore KS. Role of inflammatory mediators in thrombogenesis. J Pharmacol Exp Ther 2002;300:729-35. 
33. Lood C, Amisten S, Gullstrand B, et al. Platelet transcriptional profile and protein expression in patients with systemic lupus erythematosus: up-regulation of the type I interferon system is strongly associated with vascular disease. Blood 2010;116:1951-7.

34. Emamian ES, Leon JM, Lessard CJ, et al. Peripheral blood gene expression profiling in Sjogren's syndrome. Genes Immun 2009;10:285-96.
35. Kimoto O, Sawada J, Shimoyama K, et al. Activation of the interferon pathway in peripheral blood of patients with Sjogren's syndrome. J Rheumatol 2011;38:310-16.

36. Clemetson KJ, Clemetson JM, Proudfoot AE, et al. Functional expression of CCR1, CCR3, CCR4, and CXCR4 chemokine receptors on human platelets. Blood 2000;96:4046-54. 